O-359

J. Chem. Thermodynamics 1990, 22, 225-230

\title{
Fusion of mercury
}

\section{A new certified standard for differential scanning calorimetry ${ }^{a}$}

\author{
JANE E. CALLANAN, ${ }^{b}$ KATHLEEN M. MCDERMOTT, \\ Center for Chemical Engineering. \\ National Institute of Standards and Technology. \\ Boulder, CO 80303, U.S.A. \\ and EDGAR F. WESTRUM, JR \\ Department of Chemistry, University of Michigan, \\ Ann Arbor, MI 48109, U.S.A.
}

(Received 13 October 1989; in final form 13 November 1989)

\begin{abstract}
From the results of adiabatic-calorimetric measurements, mercury has been certified as a standard reference material for temperature and enthalpy of fusion for differential scanning calorimetry. The fusion temperature is $(234.30 \pm 0.03) \mathrm{K}$ and the molar enthalpy of fusion is $(2.301 \pm 0.001) \mathrm{kJ} \cdot \mathrm{mol}^{-1}$. Adiabatic-calorimetric measurements made by heating continuously at $0.00017 \mathrm{~K} \cdot \mathrm{s}^{-1}$ through the transition showed a fusion temperature of $(234.32 \pm 0.03) \mathrm{K}$. Differential-scanning-calorimetric measurements gave a fusion temperature of $(234.34 \pm 0.48) \mathrm{K}$.
\end{abstract}

\section{Introduction}

Many commercial differential scanning calorimeters (d.s.c.s) in general use are not absolute measuring instruments and have no Joule-calibration capability. Therefore, standards are required for calibration of both the instrument and the experimental results. The American Society for Testing and Materials (ASTM) has published recommended practices for both temperature and enthalpy calibration of a d.s.c. ${ }^{(1,2)}$

The two-point procedure for temperature calibration (E967) requires two well characterized reference materials with transition temperatures that bracket the anticipated transition temperature of the unknown; the procedure assumes that the temperature scale of the instrument is linear. ${ }^{(1)}$ The slope and the intercept of the line defined by the bracketing standards are determined. These values are applied to the observed transition temperature of the unknown material to obtain a corrected temperature.

\footnotetext{
a Work done by the National Institute of Standards and Technology. Not subject to copyright in the United States.

${ }^{b}$ To whom correspondence should be sent.
} 
The procedure recommended by ASTM for enthalpy calibration (E968) requires an adjustment to the enthalpy by use of the ratio of the literature value to the observed value for the transition enthalpy of a reference material. The temperature dependence of the enthalpy calibration factor is then taken into account by measurements of the heat capacity of $\alpha$-alumina (sapphire). ${ }^{(2)}$ Experience with this enthalpy calibration scheme in the laboratory of the National Institute of Standards and Technology-Boulder (NIST-B) has been less satisfactory than the results with the temperature calibration. ${ }^{(3)}$ Extended studies that might improve procedures for enthalpy calibration are in progress. Until a more satisfactory treatment is devised, we shall use a procedure analogous to the two-point temperature calibration.

Satisfactory materials for use as calibrants for temperature and enthalpy of transition in the sub-ambient temperature region have been difficult to find. Previous work had identified four organic compounds that were useful as temperature calibrants in this region but unsatisfactory for enthalpy calibrations. ${ }^{(4)}$ Because of the relatively high vapor pressure of these compounds at and above the melting temperature, considerable difficulty was experienced in containing them in specimen pans. The transition temperalure is relatively independent of the amount of substance present in the pan; the enthalpy of transition, however, requires an accurate sample mass. Loss of sample because of leaking specimen pans precludes the use of these organic materials as enthalpy calibrants.

Because high-purity mercury, with a fusion temperature near $234 \mathrm{~K}$, melts sharply and reproducibly, its certification as a standard was undertaken. Attempts to certify mercury by means of the procedures used for other materials in this series ${ }^{(5,6)}$ were not satisfactory because of problems with the bracketing materials, as discussed above. For this reason, the certification of mercury was undertaken by adiabatic calorimetry. This paper describes both the adiabatic-calorimetric studies and the scanning-calorimetric work.

\section{Experimental}

The mercury used for the new standard, SRM 2225, is from the stock available from the Office of Standard Reference Materials as SRM $743 .{ }^{(7)}$ It is an exceptionally pure material: the total of other elements, as determined by emission spectrographic analysis, is less than mass fraction $2 \times 10^{-8}$. The triple-point temperature of this material serves as one of the secondary reference points for IPTS-68. ${ }^{(8)}$ The melting temperature $(234.314 \mathrm{~K})$ was determined by extrapolation of the temperature at the triple point $(234.309 \mathrm{~K})$ to the temperature at the standard pressure of $101.325 \mathrm{kPa} \cdot{ }^{(9)}$ SRM 743 was shipped in an argon-filled glass ampoule; it was used and stored in our laboratory in an inert atmosphere.

For the adiabatic calorimetry, performed at the University of Michigan, $49.9807 \mathrm{~g}$ of mercury was sealed in two Pyrex glass ampoules that were placed in a gold-plated copper calorimeter (W-34) that had no internal vanes but did have a central well for the (thermometer + heater) assembly. Two flexible clips, soldered to the off-center heater, held the ampoules in place. ${ }^{(10)}$ A helium atmosphere was maintained over the mercury in the glass ampoules. After loading, the calorimeter was evacuated and 
helium was added to the vessel to a pressure of approximately $3 \mathrm{kPa}$ at $300 \mathrm{~K}$ to facilitate the attainment of thermal equilibrium. The vessel was then sealed with (indium + tin) solder. The apparent mass of the sample was converted to mass.

Calorimetric measurements were made in the Mark $X$ cryostat, which is an upgraded version of the Mark II cryostat already described. ${ }^{(11)}$ A guard shield was incorporated to surround the adiabatic shield. Heat capacities were determined between 213 and $245 \mathrm{~K}$. The enthalpy of fusion was determined from five measurements through the melting region. The results were acquired with the assistance of a computer, which was programmed for a series of determinations. ${ }^{(12)}$

The fusion temperature of mercury was determined by heating through the transition in three steps. First, the calorimeter was heated in two separate experiments to either 5 or 8 per cent of the transition range; then it was heated until the transition was 95 or 92 per cent complete. For these two steps, control parameters were adjusted so that the equilibration period lasted several hours. For the third step, the calorimeter was heated beyond the transition range, with normal parameters and equilibration period. In another measurement sequence, the temperature of the calorimeter was increased continuously at $0.00017 \mathrm{~K} \cdot \mathrm{s}^{-1}$ through the transition.

For the d.s.c. determinations, 16 specimens of mercury, with masses between 13.983 and $69.791 \mathrm{mg}$, were hermetically sealed in aluminum pans in a nitrogen atmosphere. Although these masses seem unusually large for d.s.c. specimens, the specimen volumes were very small, from 0.001 to $0.005 \mathrm{~cm}^{3}$. The absence of interaction of the mercury with the pan material was verified by examination of a specimen cell that had been in contact with liquid mercury for longer than $72 \mathrm{~h}$. Samples of 99.88 moles per cent 1-methyl-4-ethylbenzene and 99.995 moles per cent 1,2-dimethylbenzene, obtained from the American Petroleum Institute Standard Reference Materials Sample Bank, ${ }^{(13)}$ were used as bracketing reference materials. Literature values for the temperature and enthalpy of fusion were used for both reference compounds. ${ }^{(14)}$ Fusion measurements on the standards and mercury were made at a scan rate of $0.04 \mathrm{~K} \cdot \mathrm{s}^{-1}$.

The preparation of d.s.c. specimens with such small volumes of mercury was difficult. Larger, more convenient, volumes of mercury either exceeded the electronic capacity of the instrument or resulted in power against temperature curves that were misshapen and difficult to analyze. Very small volume specimens were obtained most readily by breaking small beads into smaller and smaller droplets and finally transferring one of these to the specimen pan with a capillary pipet. As with other materials in this series of standards, specimen preparation was carried out in an inert atmosphere. The exclusion of air prolonged the useful life of a standard specimen by retarding oxidation.

In the certification of the standard reference materials (SRMs) so far developed, the lightest available specimen pans were used to ensure that the mass of the empty vessel was as small a fraction of the total mass as possible. While specimen pans made from heavier materials would withstand greater pressures, their use would result in a contribution to the total heat capacity many times greater than that of the specimen itself. 
The d.s.c. specimens were also cooled through the transition several times at various rates. Again, no effect on transition properties was observed. The small volumes of mercury used in the d.s.c. cells, however, often showed a tendency to undercool. The refrigeration unit used for the d.s.c. measurements provided temperatures lower than $220 \mathrm{~K}$ only after a long delay; $220 \mathrm{~K}$ was normally not low enough to cause the mercury to solidify in a reasonable period of time. For that reason, the specimens were solidified in liquid nitrogen and transferred directly to the cold d.s.c. Crystallization to metastable states, as noted by Dumas ${ }^{(15)}$ for liquid specimens of volumes of $1 \times 10^{-3} \mathrm{~cm}^{3}$ or smaller, was not observed.

\section{Results and discussion}

The fusion temperature from the equilibrium adiabatic-calorimetric measurements was $(234.30 \pm 0.03) \mathrm{K}$. (All measured temperatures are reported on IPTS-68.) Of the mercury 84 per cent melted within a temperature interval of $0.0006 \mathrm{~K}$. When heating continuously at $0.00017 \mathrm{~K} \cdot \mathrm{s}^{-1}$, from $233.401 \mathrm{~K}$ into the transition and out of the transition to $237.912 \mathrm{~K}$, the transition began at $234.32 \mathrm{~K}$ and was complete at $234.40 \mathrm{~K}$. The slightly higher apparent fusion temperature determined in the nonequilibrium method is considered to be a consequence of slight overheating of the thermometer. This overheating was caused by the level of electrical power to the heater surrounding the thermometer in the (heater + thermometer). The effect of the power level on the apparent fusion temperature was evaluated in a separate experiment in which the transition temperature was determined at three different power levels. Doubling the power resulted in an increase of $0.018 \mathrm{~K}$ in the apparent fusion temperature, a result consistent with the higher temperatures observed in the d.s.c. measurements.

The enthalpies of fusion obtained in the five measurements on $49.9807 \mathrm{~g}$ of mercury are shown in table 1 . Information about the manner of cooling before each enthalpy run is included in table 1 . There was no evidence of any effect of thermal

TABLE 1. Enthalpy of fusion of mercury; thermal history of cooling over time $t$. Mass of sample $m=49.9807 \mathrm{~g}$, and molar mass $M=200.59 \mathrm{~g} \cdot \mathrm{mol}^{-1}$

\begin{tabular}{|c|c|c|c|c|c|}
\hline \multirow[t]{2}{*}{ Expt. no. } & \multirow[t]{2}{*}{$T / \mathrm{K}$ range } & \multirow[t]{2}{*}{$t / \mathrm{h}$} & \multicolumn{2}{|c|}{$T / \mathbf{K}$} & \multirow[t]{2}{*}{$\frac{m \Delta_{\mathrm{fus}} H_{\mathrm{m}} / M}{J}$} \\
\hline & & & in & out & \\
\hline $\mathrm{A}$ & 242 to 223 & 2.2 & 233.14 & 237.01 & 572.99 \\
\hline B & 246 to 213 & 13.8 & 233.34 & 235.34 & 573.52 \\
\hline $\mathrm{C}$ & 242 to 233 & 3.3 & 233.11 & 239.14 & $\begin{array}{l}\text { Continuous } \\
\text { heating run }\end{array}$ \\
\hline D & 239 to 183 & 2.5 & 233.27 & 236.06 & 572.79 \\
\hline $\mathrm{E}$ & 246 to 221 & 1.5 & 233.25 & 236.44 & 573.48 \\
\hline \multirow[t]{2}{*}{$F$} & 241 to 217 & 9 & 233.14 & 236.38 & 573.26 \\
\hline & \multicolumn{4}{|c|}{$\begin{array}{l}\left\langle m \Delta_{\text {fus }} H_{\mathrm{m}} / M\right\rangle=(573.208 \pm 0.315) \mathrm{J} \\
\left\langle\Delta_{\mathrm{tus}} H_{\mathrm{m}} / M\right\rangle=(11.469 \pm 0.006) \mathrm{J} \cdot \mathrm{g}^{-1} \\
\left\langle\Delta_{\mathrm{fus}} H_{\mathrm{m}}\right\rangle=(2.301 \pm 0.001) \mathrm{kJ} \cdot \mathrm{mol}^{-1}\end{array}$} & \\
\hline
\end{tabular}


TABLE 2. Literature values for temperature and molar enthalpy of fusion of mercury $\left(M=200.59 \mathrm{~g} \cdot \mathrm{mol}^{-1}\right)$

\begin{tabular}{|c|c|c|}
\hline$\frac{T_{\text {fus }}}{\mathrm{K}}$ & $\frac{\Delta_{\mathrm{fus}} H_{\mathrm{m}}}{\mathrm{kJ} \cdot \mathrm{mol}^{-1}}$ & Method \\
\hline & 2.343 & $\left(p, V_{\mathrm{m}}, T\right)^{(18)}$ \\
\hline 234.45 & 2.320 & Nernst calorimeter ${ }^{(19)}$ \\
\hline 234.31 & 2.295 & Isoperibol calorimeter ${ }^{(16)}$ \\
\hline 233.15 & & D.t.a. ${ }^{(20)}$ \\
\hline \multirow{3}{*}{234.314} & 2.434 & D.t.a. ${ }^{(21)}$ \\
\hline & & Triple point ${ }^{(9)}$ \\
\hline & $\begin{array}{l}2.308^{a} \\
2.313^{b}\end{array}$ & Pressure d.s.c. ${ }^{(22)}$ \\
\hline 234.30 & 2.301 & Adiabatic calorimetry (this work) \\
\hline 234.34 & & D.s.c. (this work) \\
\hline
\end{tabular}

${ }^{a}$ Experimental. ${ }^{b}$ Extrapolated.

history on the transition properties of the mercury. The average value of the specific enthalpy of fusion: $(11.469 \pm 0.006) \mathrm{J} \cdot \mathrm{g}^{-1}$, corresponds to a molar ethalpy of fusion of $(2.301 \pm 0.001) \mathrm{kJ} \cdot \mathrm{mol}^{-1}$ (molar mass of mercury: $200.59 \mathrm{~g} \cdot \mathrm{mol}^{-1}$ ).

Values reported by Busey and Giauque, ${ }^{(16)} 234.31 \mathrm{~K}$ and $(2.2953 \pm 0.0004)$ $\mathrm{kJ} \cdot \mathrm{mol}^{-1}$, are recommended in the most recent edition of the JANAF tables. ${ }^{(17)}$ A summary of literature values is given in table 2 .

The fusion temperature obtained from the 16 d.s.c. measurements was $(234.34 \pm 0.48) \mathrm{K}$. The results for the measurements of the specific enthalpy of fusion varied by $0.1 \mathrm{~J} \cdot \mathrm{g}^{-1}$; the standard deviation was 0.03 per cent. Though it was not possible to use our customary correction procedures for enthalpy, as explained above, these values are cited here to indicate the precision of the enthalpy measurements and to demonstrate the suitability of mercury as a reference material. The purity manifested by the remarkably narrow melting range was evident also in the very sharp d.s.c. scans. The fusion scan showed no signs of premelting or defect solid structure. ${ }^{(23)}$

The certification of mercury ${ }^{(24)}$ as a calibrant for scanning calorimetry and other thermal-analytical procedures provides a long-sought reliable calibrant in the subambient temperature region. (SRM 2225 is distributed in a vial with a septum and a seal that can be open and closed; specimens of appropriate size can readily be prepared by means of a hypodermic syringe inserted through the septum.) Mercury specimens sealed in an inert atmosphere, in use for three years in our laboratory, have shown no degradation in the quality of the scans or the reproducibility of the temperature and enthalpy of fusion. Because the vapor pressure of mercury at its melting temperature is small, no problems were experienced with leaking specimen pans.

The recent heat-capacity measurements of Amitin and colleagues ${ }^{(25-27)}$ were made entirely in the solid region and provide no results for comparison with this work. The aim of their work was to provide information that would allow for examination of the theoretical description of the melting process in the vicinity of the melting 
temperature. To this end, they made approximately 250 heat-capacity measurements in the temperature range 170 to $234 \mathrm{~K}$. In our work, no attempt was made to redetermine the heat capacity of mercury in either solid or liquid form since excellent values $^{(16)}$ are available. Only the heat capacity of the system, as distinct from the heat capacity of mercury, was determined.

\section{REFERENCES}

1. American Society for Testing and Materials (ASTM). Standard Practice E967-83. Annual Book of Standards. 1988, 14-02, 583.

2. American Society for Testing and Materials (ASTM). Standard Practice E968. Annual Book of Standards. 1988, 14-02, 587.

3. Callanan, J. F.; Sullivan, S. A.; Vecchia, D. F. Natl. Bur. Stand. (U.S.) Special Publication 260-99. 1985.

4. Callanan, J. E.; McDermott, K. M.; Sullivan, S. A. Thermochimica Acta, submitted for publication.

5. Callanan, J. E.; Sullivan, S. A.; Vecchia, D. F. J. Res. Natl Bur. Stand. (U.S.) 1986, 91, 123.

6. Callanan, J. E.; Sullivan, S. A. Rev. Sci. Instrum. 1986, 57, 2584.

7. Office of Standard Reference Materials. National Institute of Standards and Technology, Gaithersburg, MD 20899, USA.

8. Metrologia 1976, 12, 7 .

9. National Bureau of Standards (U.S.) Standard Reference Material Certificate, SRM 743, Mercury. 1976.

10. Westrum, E. F., Jr.; Burriel, R.; Gruber, J. B.; Palmer, P. E.; Beaudry, B. J.; Plautz, W. A. J. Chem. Phys. 1989, 91, 4838.

11. Westrum, E. F., Jr.; Furukawa, G. T.; McCullough, J. P. Experimental Thermodynamics, Vol. I. McCullough, J. P.; Scott, D. W.: editors. Butterworths: London. 1968, p. 133.

12. Westrum, E. F., Jr. Proceedings NATO Advanced Study Institute on Thermochemistry at Viana do Castello, Portugal. Ribeiro da Silva, M. A. V.: editor. Reidel: New York. 1984, p. 745.

13. American Petroleum Institute Standard Reference Material. Carnegie-Mellon University. Pittsburgh, PA.

14. Rossini, F. D.; Pitzer, K. S.; Amett, R. L.; Braun, R. M.; Pimentel, G. C. Selected Values of Physical and Thermodynamic Properties of Hydrocarbons and Related Compounds. Carnegie: Pittsburgh. 1953.

15. Dumas, J. P. J. Phys. C 1976, 9, L143.

16. Busey, R. H.; Giauque, W. F. J. Am. Chem. Soc. 1953, 75, 806.

17. Chase, M. W., Jr.; Davies, C. A.; Downey, J. R., Jr.; Frurip, D. J.; McDonald, R. A.; Syverud, A. N. JANAF Thermochemical Tables, 3rd edition. J. Phys. Chem. Ref. Data 1985, 14, 1319. Supplement 1.

18. Bridgman, P. W. Proc. Nat. Acad. Sci. 1911, 47, 347.

19. Pollitzer, F. Z. Elektrochem. 1911, 17, 5.

20. Markowitz, M. M.; Boryta, D. A. Anal. Chim. Acta 1964, 31, 397.

21. Pouillen, P.; Saurel, J. Compt. Rend. 1968, 266C, 1661.

22. Putten, L, van der; Schouten, J. A.; Trappeniers, N. J. High Temp.-High Press. 1984, 16, 281.

23. Hayes, W. Contemp. Phys. 1986, 27, 519.

24. National Bureau of Standards (U.S.) Standard Reference Material-2225. Temperature and Enthalpy of Fusion-Mercury.

25. Amitin, E. B.; Minenkov, Yu. F.; Nabutovskaya, O. A.; Paukov, I. E. J. Chem. Thermodynamics 1986, 18, 423 .

26. Amitin, E. B.; Lebedeva, E. G.; Paukov, I. E. Zh. Fiz. Khim. 1979, 53, 2666.

27. Amitin, E. B.; Minenkov, Yu. F.; Nabutovskaya, O. A.; Paukov, E. E. Sov. Phys. JETP 1985, 62, 1207. 